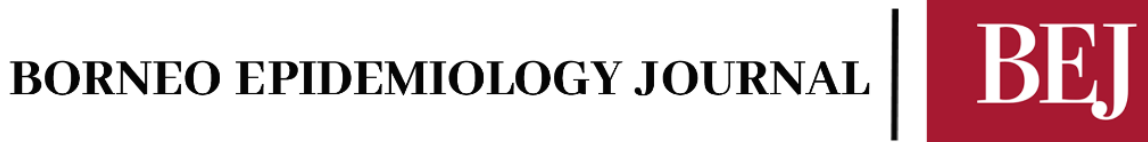

\section{COVID-19 Cluster in School: A Study on Epidemiology and Clinical Manifestations among Cases from Rengas Cluster in Perak, Malaysia}

Syahrizal Abdul Halim,* Nor Azila Muhd Aris, Muhammad Zikri Fadzil, Husna Maizura Ahmad Mahir

\section{Abstract}

Background: A COVID-19 cluster named as Rengas Cluster was declared on $6^{\text {th }}$ November 2020 after nine students from a boarding school in Padang Rengas, Perak diagnosed as positive COVID-19. Risk assessment was conducted and Targeted Enhanced Movement Control Order (TEMCO) was enforced at the school to contain the viral transmission. An investigation was carried out to analyze epidemiological data, clinical manifestations among cases and effect of TEMCO on this cluster.

Methods: A retrospective cross-sectional study was conducted from $2^{\text {nd }}$ August 2021 until $3^{\text {rd }}$ September 2021 using data that obtained from Kuala Kangsar District Health Office Crisis Preparedness and Response Centre (CPRC) Surveillance System through $e$-COVID notification system. The variables used in this current study include socio-demographic and clinical characteristics that include age group, gender, occupation, co-morbidities, symptoms and signs.

Results: There were 132 cases out of 324 exposed populations whereby most cases were students (87.9\%) and aged between 11 and 20 years old (84.8\%). More than half of cases were female $(57.6 \%)$ with only one case had existing co-morbidity. Majority of cases were asymptomatic $(64.4 \%)$. Those symptomatic mainly presented with cough $(66 \%)$ and the strongest significant positive correlation were observed between anosmia and ageusia ( $r=0.807, \mathrm{n}=47, p<0.001)$. There was no significant association between age group and development of symptoms $\left[\chi^{2}(6, \mathrm{~N}=132)=6.014, p>0.05\right]$. An abrupt decline in number of cases was observed following TEMCO enforcement.

Conclusion: COVID-19 cases in Rengas Cluster were mostly among young students, asymptomatic and mildly symptomatic. This cluster was timely and effectively controlled by TEMCO enforcement which contributed towards early diagnosis, isolation and treatment for more effective control and preventive measures.

Keywords: COVID-19, Cluster, Clinical Manifestation, School, TEMCO.
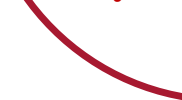

*Correspondence Email: syahrizalabdulhalim@yahoo.com

Kuala Kangsar District Health Office, Ministry of Health Malaysia, Jalan Sultan Idris Shah 1, 33000 Kuala Kangsar, Perak, Malaysia

Received: 20/12/2021

Accepted: 27/12/2021 


\section{Introduction}

Coronavirus disease (COVID-19) is a novel viral infectious respiratory disease that affects all age group of people worldwide with elderly and those having medical comorbidities are at higher risk of developing severe complication (CDCP,2021). COVID-19 virus is transmitted by human-to-human contact mainly through respiratory droplet (World Health Organization, 2020). This disease was declared as Public Health Emergency of International Concern (PHEIC) by the World Health Organization (WHO) on $11^{\text {th }}$ March 2020 (WHO, 2020). Malaysia had recorded its first COVID-19 case on $24^{\text {th }}$ January 2020 involving a Chinese national tourist who entered Malaysia from Singapore (Shakirah et al., 2020). Subsequently, the disease spread massively into the community and later contributing to the presence of large and small clusters involving both locally transmitted and imported cases.

Malaysia had reported 33,339 and 251 COVID-19 cases and mortalities respectively until $2^{\text {nd }}$ November 2020 (Worldometer, 2021). Meanwhile, Perak state recorded 519 and 7 COVID-19 cases and mortalities respectively until $2^{\text {nd }}$ November 2020 (Malaysia Ministry of Health, 2020). The transmission of COVID-19 in closed institution such as a boarding school is usually faster than others as the students living in the hostel due to living environment that may not feasible to practice precautionary measures at all times. Thus, COVID-19 cluster may easily spark in the institution once the virus introduced there either by students themselves, staff or visitors.

Rengas Cluster (Ministry of Health Malaysia, 2020) that involved nine students from a boarding school in Padang Rengas, Perak who were diagnosed as positive COVID-19 was declared on $6^{\text {th }}$ November 2020. It was named based on the location of the school namely in Padang Rengas. The index cases were two students who stayed in the same school hostel following Influenza-Like-Illness (ILI) screening for being symptomatic since $2^{\text {nd }}$ November 2020. Both of them were merely staying within the school compound during incubation period. Subsequently, they were admitted to a tertiary hospital in Ipoh, Perak on $4^{\text {th }}$ November 2020.

Kuala Kangsar District Health Office had vigilantly taken intensive control and preventive measures by initiating Targeted Enhanced Movement Control Order (TEMCO) that implied total lockdown in a specific locality such as school (Majlis Keselamatan Negara, 2021). This approach is taken in order to prevent the spread of disease into the community outside the institution that may lead the COVID-19 cluster to be prolonged and become uncontrolled. The objectives of this study are to analyze epidemiological data, clinical manifestation among cases related to this cluster and effect of TEMCO enforcement on this cluster.

\section{Materials \& Methods}

\section{Location and Population of Study}

This school is located approximately $12 \mathrm{~km}$ distance from Kuala Kangsar Royal Town in Perak, Malaysia that comprises of 238 students, 33 teachers, 5 administration staff, 6 dining hall staff, 4 canteen staff, 4 cleaners and 9 security officers. The cases that included in this study were students and staff of the schools as well as those outside the school but had epidemiological link with the cluster which mostly the student's parents and siblings. The nearest government health clinic is Klinik Kesihatan Padang Rengas (about 850 meters apart by main road), whereas the closest government hospital is Hospital Kuala Kangsar (about 10 $\mathrm{km}$ distance by main road). 


\section{Study design and data collection procedure}

This was a retrospective cross-sectional study using universal sampling method involving all 132 COVID-19 positive cases with epidemiological-link to Rengas Cluster from $2^{\text {nd }}$ November 2020 until $24^{\text {th }}$ December 2020. These cases include students and staff of the school as well as those outside the school that had epidemiological link with the cluster. This sampling method was used as all cases were taken as the respondents in view of all of them may provide useful information to test the hypothesis of this study. In fact, all people in the population have different probability of being included in the sample with each one of them has unknown probability of being selected (Richard and Margaret, 1990).

This study was conducted from $2^{\text {nd }}$ August 2021 until $3^{\text {rd }}$ September 2021 using data that obtained from Kuala Kangsar District Health Office Crisis Preparedness and Response Centre (CPRC) Surveillance System through e-COVID (online notification system for COVID-19 cases, managed by Ministry of Health Malaysia). The variables used in this current study include socio-demographic and clinical characteristics that include age group, gender, occupation, co-morbidities, symptoms and signs.

\section{Case Definition}

Ministry of Health Malaysia (2021) had outlined a case definition of COVID-19 that refers to anyone with positive reverse transcriptase polymerase chain reaction (RTPCR) regardless of presence of any clinical manifestation. Meanwhile, cluster is defined as epidemiologicallylinked group of cases such as in educational institution, community and other settings.

All cases in this study had undergone swabs of nasopharyngeal and oropharyngeal whereby all their clinical specimens were sent to either National Public Health Laboratory or Hospital Raja Permaisuri Bainun in Ipoh, Perak to be tested for COVID-19 using RTPCR method with calculated Cycle Threshold (CT) Value. The CT Value is a quantitative measurement that recommended to be used in predicting viral load, disease severity and infectivity as well as provides information on underlying viral dynamics (Rabaan et al., 2021). This is a potential indicator for local outbreaks (Tso et al., 2021) and may assist in estimating epidemic growth rate towards planning the effective and more targeted epidemiological measures to control the epidemic.

\section{Data entry and analysis}

Data were coded, manually checked for any inconsistencies, duplication or missing values, statistical assumptions including the normality of data distribution and analysed using the statistical package for social science (SPSS) Version 21.0. Descriptive, Chi-Square for Independence and Pearson product-moment correlation analysis were conducted with data presented in both tabular and figure forms. The quantitative data were presented in mean, minimum, maximum and standard deviation (SD) whereas qualitative data were presented in frequency and percentage. The epidemic curve was constructed based on date of onset for symptomatic cases and date of positive sample taken for asymptomatic cases. 


\section{Results}

\section{Socio-demographic characteristics}

A total of 132 cases out of 324 exposed population were detected with majority of cases aged between 11 and 20 years old $(84.8 \%)$ [mean (SD) age of 17.91 (10.03)]. Most cases were students $(87.9 \%)$ particularly from the school where the cluster is identified, followed by teacher $(3.8 \%)$, unemployed $(3.8 \%)$, nurse $(2.3 \%)$, administrator $(1.5 \%)$ and police officer $(0.8 \%)$. The male cases were less than females with $42.4 \%$ and $57.6 \%$ respectively. There was only one case with co-morbidity (0.8\%). These findings are summarized in Table 1 as below.

Table 1: Socio-demographic characteristics of cases $(n=132)$

\begin{tabular}{lcc}
\hline Characteristics & Frequency & Percentage \\
\hline Age Group (Years) & 4 & 3.0 \\
$0-10$ & 112 & 84.8 \\
$11-20$ & 4 & 3.0 \\
$21-30$ & 5 & 3.8 \\
$31-40$ & 3 & 2.3 \\
$41-50$ & 2 & 1.5 \\
$51-60$ & 2 & 1.5 \\
More than 60 & $17.91(10.03)$ & \\
Mean (SD) Age & 1 & \\
Minimum & 66 & \\
Maximum & & 42.4 \\
Gender & 56 & 57.6 \\
Male & 76 & \\
Female & & 87.9 \\
Occupation & 116 & 2.3 \\
Student & 3 & 3.8 \\
Nurse & 5 & 0.8 \\
Teacher & 1 & 1.5 \\
Police Officer & 2 & 3.8 \\
Administrator & 5 & 0.8 \\
Unemployed & 131 & 9.2 \\
Co-morbidity & & \\
Yes & 1 & \\
No & & \\
\hline
\end{tabular}

\section{Epidemiological Investigation}

Figure 1 below shows an epidemic curve whereby cases were initially detected among those symptomatic and gradually increased before a sudden spike of cases especially among those asymptomatic. The number of cases was gradually decreased towards the end of the outbreak. Altogether, there were 2820 close contacts to COVID-19 cases identified with ratio for case to close contact of 1:21. 


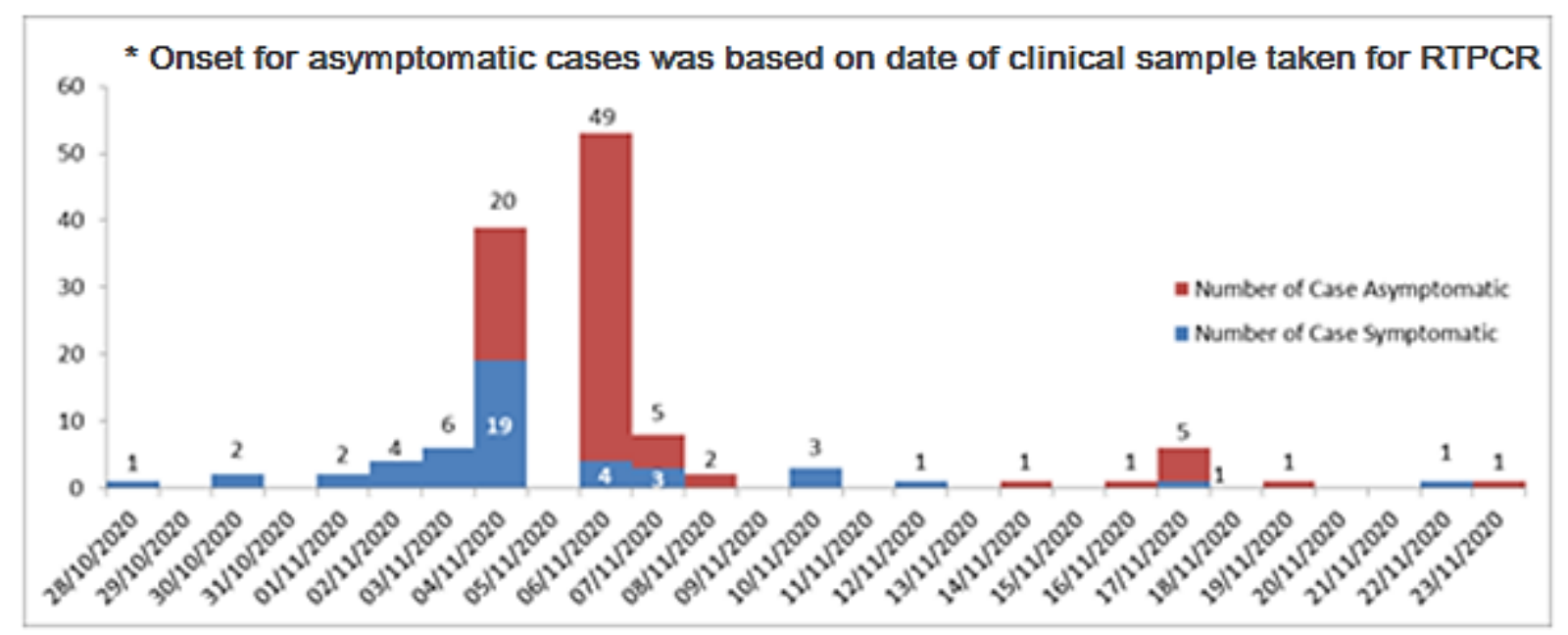

Figure 1: Epidemic Curve of Rengas Cluster $(\mathrm{N}=132)$

Classification of Symptoms

Asymptomatic cases constituted for more than half of cases (64.4\%) as shown in Table 2. Meanwhile, Figure 2 showed that more than half of symptomatic cases presented with cough (66\%) compared to other symptoms.

Table 2: Classification of symptoms among cases $(n=132)$

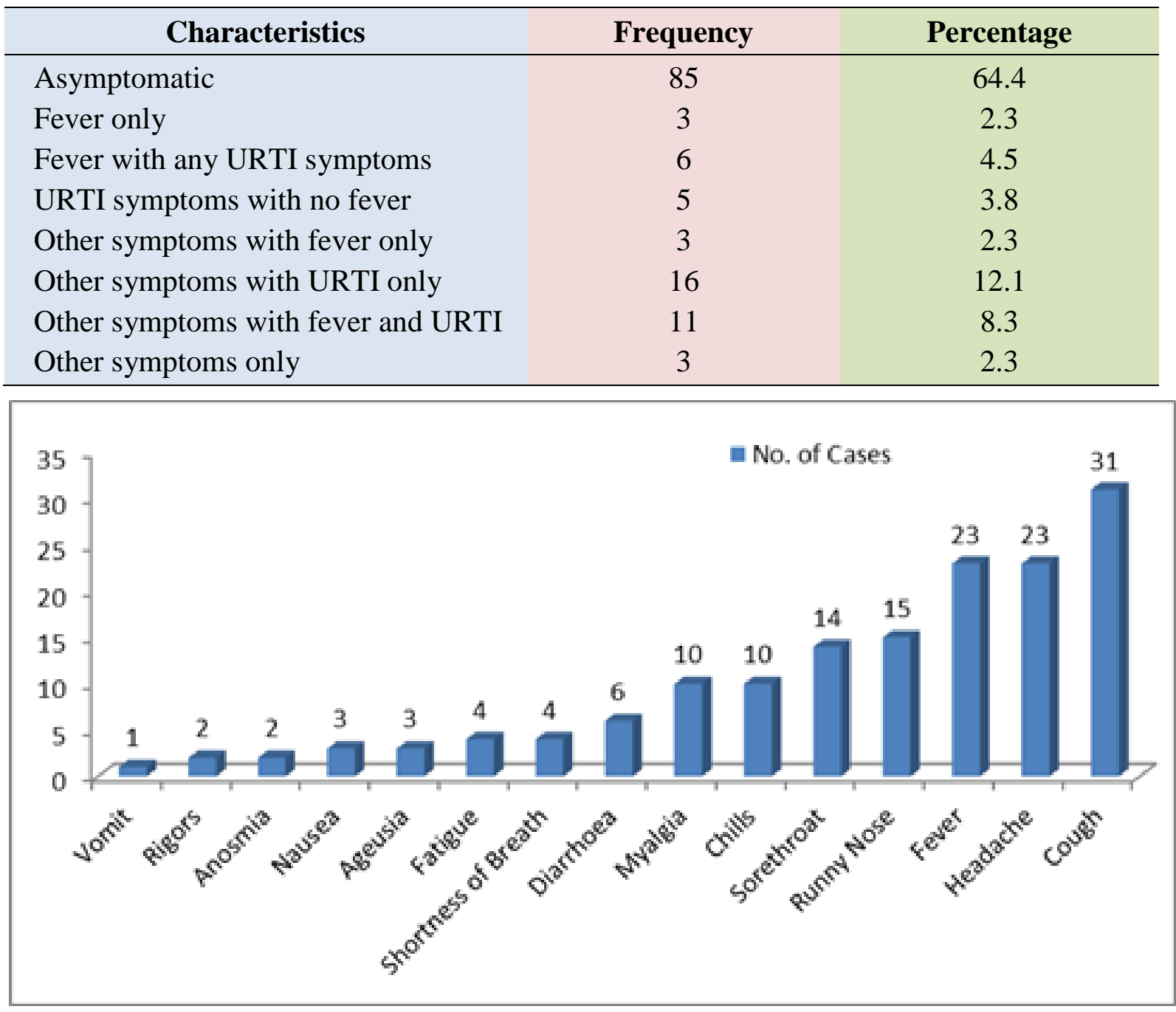

Figure 2: Number of symptomatic cases based on type of symptom $(n=47)$ 


\section{Association between COVID-19 symptoms}

A Pearson product-moment correlation was carried out to determine the relationship between each individual symptom that may indicate the significant pair of symptoms experienced by cases. There were statistically significant $(p<0.05)$ positive and strong correlation between anosmia and ageusia $(r=0.807, \mathrm{n}=47, p=0.000)$, chills and diarrhea $(r=0.580, \mathrm{n}=47, p=$ $0.000)$ as well as nausea and vomit $(r=0.565, \mathrm{n}=47, p=0.000)$. Meanwhile, statistically significant $(p<0.05)$ positive and moderate correlation was observed between chills and headache $(r=0.427, \mathrm{n}=47, p=0.003)$, rigors and myalgia $(r=0.406, \mathrm{n}=47, p=0.005)$, chills and rigors $(r=0.406, \mathrm{n}=47, p=0.005)$, chills and myalgia $(r=0.365, \mathrm{n}=47, p=$ $0.012)$, rigors and sore throat $(r=0.324, \mathrm{n}=47, p=0.026)$ as well as headache and myalgia $(r$ $=0.323, \mathrm{n}=47, p=0.027)$. Table 3 summarizes these findings.

Table 3: Significant correlation between each individual symptom

\begin{tabular}{ccccc}
\hline \multicolumn{1}{c}{ Symptom } & & Pearson correlation, $\boldsymbol{r}$ & Sig. \\
\cline { 1 - 2 } Anosmia & $\mathbf{2}$ & 0.807 & 0.000 \\
Chills & Ageusia & 0.580 & 0.000 \\
Nausea & Diarrhoea & 0.565 & 0.000 \\
Chills & Vomit & 0.427 & 0.003 \\
Rigors & Headache & 0.406 & 0.005 \\
Chills & Myalgia & 0.406 & 0.005 \\
Chills & Rigors & 0.365 & 0.012 \\
Rigors & Myalgia & 0.324 & 0.026 \\
Headache & Sore throat & 0.323 & 0.027 \\
\hline
\end{tabular}

Factors associated with development of COVID-19 symptom(s)

A Chi Square test for independence was conducted to analyse the association between gender and development of symptoms as well as between age group and development of symptoms. More than half of symptomatic cases were female (53.2\%) as compared to male (46.8\%). However, there was no significant association between gender and development of symptoms whereby $\chi^{2}(1, \mathrm{~N}=47)=0.574, p=0.449(p>0.05)$. Furthermore, more than three-quarter of symptomatic cases were those aged from 11 to 20 years old $(83.0 \%)$. However, there was no significant association between age group and development of symptoms whereby $\chi^{2}(6, \mathrm{~N}=$ $47)=6.014, p=0.422(p>0.05)$.

\section{Discussion}

The most affected age group in this Rengas cluster was those aged between 11 and 20 years old. In fact, most cases were among students staying in the boarding school whom aged between 13 to 18 years old. A boarding school is a closed institution that is potentially high risk for COVID-19 viral transmission. Therefore, appropriate and strict gate keeping is crucial. 
Meanwhile, the highest overall incidence of COVID-19 incidence in the United States from $1^{\text {st }}$ March 2020 to $14^{\text {th }}$ November 2020 was among those aged between 18 to 24 years old even though those aged more than 80 years had the highest incidence during the initial phase of pandemic (Duca et al., 2021). Furthermore, those aged below 19 years old recorded the second highest number of cases in Canada as of $26^{\text {th }}$ March 2021 (Government of Canada, 2021). This indicates the recent trend of higher cases among younger adults.

Furthermore, majority of the cases in this cluster were female which is contradictory to finding from a nationwide observational study in Malaysia by Sim et al. (2020) whereby male constituted almost three-quarter of cases (71.7\%). Meanwhile, similar proportion between male (48.9\%) and female $(51.1 \%)$ was reported in Canada (Government of Canada, 2021). However, higher cases among female in this cluster may be influenced by higher proportion of female students in this school $(52.5 \%)$ as well as higher cases among female lives outside school compound that epidemiologically-linked to this cluster $(85.7 \%)$ as compared to male.

Next, asymptomatic cases constituted for more than half of cases in this cluster. However, a study by Oran (2020) had discovered that a lower proportion of asymptomatic COVID-19 cases in 16 different cohorts at around $40 \%$ to $45 \%$. Identification of asymptomatic case in a community is very challenging because no one knows of being infected unless they are screened over the course of infection. Although asymptomatic cases had $42 \%$ lower transmission rates than symptomatic cases (Byambasuren et al., 2020), higher proportion of asymptomatic cases in this current cluster indicates the needs to empower practices of hand hygiene, face mask and social distancing as well as enhancing contact tracing by targeting low positivity rate and improvise isolation strategies.

Cough, headache and fever were the most common symptoms experienced among those symptomatic cases in this cluster. A systematic review by Mesquita et al. (2020) had discovered that cough and fever were the most common symptoms presented by positive COVID-19 patients (54.5\% and 58.7\% respectively) but headache was observed in merely $12.2 \%$ of cases only. Similarly, cough and fever were the most commonly observed among Malaysians with $32.2 \%$ and $29.5 \%$ respectively (Sim et al., 2020). Furthermore, those symptomatic cases were mostly experiencing upper respiratory tract infection (URTI) with other symptoms only $(12.1 \%)$ but significant correlation was merely observed between sore throat and rigors. The other significant correlation between symptoms was only recognized between symptoms other than fever and any URTI symptoms. Conversely, a study in Shenzhen by Luo et al. (2020) discovered significant correlation between eight pairs of symptoms namely expectoration-cough, expectoration-wheezing, palpitation-fever, palpitation-diarrhoea, dry mouth-bitter taste in mouth, fatigue-poor appetite, dizziness-fatigue and dizziness-headache. Our findings had also shown no significant association of age group and gender with development of symptoms. However, different distribution of comorbidity in different setting may affect this relationship (Clark et al., 2020). Thus, the distribution of cases that largely involved those within a school in Rengas cluster aged between 11 to 20 years old may contribute to this non-significant association.

Moreover, this cluster had initially shown a gradual increase with a sudden surge in number of cases. This had alerted the Kuala Kangsar District Health Office to enforce Targeted Enhanced Movement Control Order (TEMCO) in the affected school for this cluster with the support from the District Disaster Management Committee. The objective was mainly to reduce the risk of widespread transmission of the disease in the school with preventing viral introduction into the school by those especially staff who commute daily. 
In fact, this is the first educational institution in Perak being enforced with TEMCO. This was a wise decision as enforcing Enhanced Movement Control Order (EMCO) for the whole sub-district may be more effective but highly potential to adversely affect the economy. The effectiveness of TEMCO is evidenced by abrupt decline in number of cases following its implementation from $8^{\text {th }}$ November 2020 until $30^{\text {th }}$ November 2020. All cases were admitted to hospital for isolation and treatment whereas all close contacts were either quarantined in the school or other gazetted quarantine centres in Sungkai and Ipoh, Perak. Therefore, TEMCO in Rengas cluster had assisted in early identification of cases regardless of symptomatic status as well as timely isolation of case and quarantine of close contacts to effectively interrupt the spread of disease.

\section{Strength, Limitation and Recommendation}

Our study focused on a COVID-19 cluster in a closed institution that is beneficial to be compared with community cluster. However, our data was limited to cases with similar sociodemographic background and culture. Thus, it is recommended for this study to be expanded involving all clusters in Kuala Kangsar district to compare the differences between cluster underwent TEMCO and vice versa as well. Furthermore, strict gate keeping with early isolation and quarantine of cases and close contacts respectively are crucial in managing cluster in any boarding school. Moreover, all students and staff should be vaccinated before school re-open.

\section{Conclusion}

Rengas cluster involved mainly those students in affected school with most cases were asymptomatic. However, cough, headache and fever are the most common clinical manifestations whereby age and gender were not significantly associated with symptoms development. In the absence of vaccine availability during this cluster, timely enforcement of TEMCO that had managed to identify, isolate and treat all cases at early stage was subsequently had controlled the spread of the cluster at early stage successfully.

\section{Conflicts of Interest}

This research has no conflicts of interests.

\section{Funding Statement}

Nil.

\section{Ethical Approval}

An ethical approval for this study was obtained from Medical Research and Ethics Committee (MREC) of Ministry of Health Malaysia on $16^{\text {th }}$ July 2021 [Reference number: NMRR-211346-59338 (IIR)].

\section{Acknowledgments}

The authors would like to thank Director-General of Health Malaysia for his permission to publish this article. 


\section{References}

Byambasuren, O., Byambasuren, O., Cardona, M., Bell, K.J.L., Clark, J., Mclaws, M.L., Glasziou, P. (2020). Estimating the Extent of Asymptomatic COVID-19 and its Potential for Community Transmission: Systematic Review and Meta-analysis. Official J. Assoc. Med. Microbiol. Infect. Dis. Can., 5(4), 223-234. https://doi.org/10.3138/jammi-2020-0030

CDC (Centres for Disease Control and Prevention). (2021). COVID-19: Frequently Asked Questions. Retrieved from Centres for Disease Control and Prevention. https://www.cdc.gov/coronavirus/2019-ncov/faq.html

Clark, A., Jit, M., Warren, G.C., Guthrie, B., Wang, H.H.X., Mercer, S.W., Sanderson, C., McKee, M., Troeger, C., Ong, K.L., Checchi, F., Perel, P., Joseph, S., Gibbs, H.P., Banerjee, A., Eggo, R.M. . (2020). Global, Regional, and National Estimates of the Population at Increased Risk of Severe Covid-19 due to Underlying Health Conditiions in 2020: A Modelling Study. Lancet Glob. Health, e1003-e1017. https://doi.org/10.1016/s2214-109x(20)30264-3

Duca, L.M., Xu, L., Price, S.F., McLean, C.A. (2021). COVID-19 Stats: COVID-19 Incidence, by Age Group - United States, March 1 - November 14, 2020. Morbidity and Mortality Weekly Report (MMWR): Centers for Disease Control and Prevention, 1664. Retrieved from Centers for Disease Control and Prevention (CDCP). https://www.cdc.gov/mmwr/volumes/69/wr/mm695152a8.htm

Government of Canada. (2021). Coronavirus disease 2019 (COVID-19): Epidemiology Update. Retrieved from Government of Canada: https://health-infobase.canada.ca/covid19/epidemiological-summary-covid-19-cases.html

Luo, Y., Wu, J., Lu, J., Xu, X., Long, W., Yan, G., Tang, M., Zou, L., Xu, D., Zhuo, P., Si, Q., Zheng, X. (2020). Investigation of COVID-19-related symptoms based on factor analysis. Annals of Palliative Medicine, 1851-1858. https://doi.org/10.21037/apm-20-1113

Majlis Keselamatan Negara. (2021). SOP Perintah Kawalan Pergerakan. Retrieved from Majlis Keselamatan Negara: http://mkn.gov.my/web/ms/sop-perintah-kawalan-pergerakan/

Mesquita, R.D.R., Junior, L.C.F.S., Santana, F.M.S., Oliveira, T.F.D., Alcantara, R.C., Arnozo, G.M., Filho, E.R.D.S., Santos, A.G.G.D., Cunha, E.J.O.D., Aquino, S.H.S.D., Souza, C.D.F.d. (2020). Clinical Manifestation of COVID-19 in the General Population: Systematic Review. Wien. Klin. Wochenschr., 133 (7-8), 377-382. https://doi.org/10.1007/s00508020-01760-4

MHM (Ministry of Health Malaysia). (2020). Kemaskini Negeri Sehingga 02 November 2020. Retrieved from Kementerian Kesihatan Malaysia: COVID-19 Malaysia: https://covid19.moh.gov.my/terkini-negeri/112020/kemaskini-negeri-sehingga-02-november-2020

MHM (Ministry of Health Malaysia). (2020). Tiga (3) Kluster Baharu Dilaporkan Hari Ini (06/11/2020). Retrieved from COVID-19 Malaysia: Kementerian Kesihatan Malaysia. https://covid-19.moh.gov.my/sorotan/112020/tiga-3-kluster-baharu-dilaporkan-hari-ini$\underline{06112020}$

MHM (Ministry of Health Malaysia). (2021). Garis Panduan Kementerian Kesihatan Malaysia. Retrieved from COVID-19 Malaysia: Kementerian Kesihatan Malaysia. https://covid19.moh.gov.my/garis-panduan/garis-panduan-kkm

Oran, D.P., Topol. E.J. (2020). Prevalence of Asymptomatic SARS-CoV-2 Infection: A Narrative Review. Ann. Intern. Med., 173(5), 362-367. https://doi.org/10.7326/m20-3012

Rabaan, A.A., Tirupathi, R., Sule, A.A., Aldali, J., Mutair, A.A., Alhumaid, S., Muzaheed, Gupta, N., Koritala, T., Adhikari, R., Bilal, M., Dhawan, M., Tiwari, R., Mitra, S., Emran, T.B., Dhama, K. (2021). Viral Dynamics and Real-Time RT-PCR Ct Values Correlation with Disease Severity in COVID-19. Diagnostics (Basel), 11(6), 1091(1-18). https://doi.org/10.3390/diagnostics11061091 
Richard, M.G., Margaret, W. (1990). Research in Social Work: A Primer. Michigan: F.E. Peacock Publishers. https://www.amazon.com/Research-RIchard-Grinnell-MargaretWilliams/dp/087513372X

Shakirah, M.S., Ang, Z.Y., Anis-Syakira, J., Cheah, K.Y., Kong, Y.L., Selvarajah, S., Balqis-Ali, N.Z., Fun, W.H., Sararaks, S. (2020). The COVID-19 Chronicles of Malaysia: In the face of a pandemic. Setia Alam, Selangor: National Institutes of Health.

https://maera.nih.gov.my/index.php/component/advportfoliopro/project/41-the-covid-19chronicles-of-malaysia-edition-3

Sim, B.L.H., Chidambaram, S.K., Wong, X.C., Pathmanathan, M.D., Peariasamy, K.M., Hor, C.P., Chua, H.J., Goh, P.P. (2020). Clinical Characteristics and Risk fFactors for Severe COVID-19 Infections in Malaysia: A Nationwide Observational Study. Lancet Reg. Health West. Pac., 4, 100055(1-8). https://doi.org/10.1016/j.lanwpc.2020.100055

Tso, C.F., Garikipati, A., Green-Saxena, AA., Mao, Q., Das, R. (2021). Correlation of Population SARS-CoV-2 Cycle Threshold Values to Local Disease Dynamics: Exploratory Observational Study. JMIR Public Health Surveill., 2021, 7(6), e28265(1-11). https://doi.org/10.2196/28265

WHO (World Health Organization). (2020). Coronavirus disease (COVID-19): How is it transmitted? Retrieved from World Health Organization. https://www.who.int/news-room/questions-andanswers/item/coronavirus-disease-covid-19-how-is-it-transmitted

WHO (World Health Organization). (2020). WHO Director-General's Opening Remarks at the Media briefing on COVID-19, 11 March 2020. https://www.who.int/directorgeneral/speeches/detail/who-director-general-s-opening-remarks-at-the-media-briefing-oncovid-19---11-march-2020

Worldometer. (2021). Total Coronavirus Cases in Malaysia. https://www.worldometers.info/coronavirus/country/malaysia/ 